Article No 229

DOI: https://doi.org/10.26881/srg.2020.7.04

Citation:

Хоригути, Д. (2020). Префикс за- в сочетании с заимствованными глаголами

в русском языке. Studia Rossica Gedanensia, 7: 49-58.

DOI: https://doi.org/10.26881/srg.2020.7.04

Horiguti, D. (2020). Prefiks $z a-\mathrm{v}$ sočetanii s zaimstvovannymi glagolami v russkom âzyke.

Rossica Gedanensia, 7: 49-58.

DOI: https://doi.org/10.26881/srg.2020.7.04

\title{
ПРЕФИКС ЗА- В СОЧЕТАНИИ С ЗАИМСТВОВАННЫМИ ГЛАГОЛАМИ В РУССКОМ ЯЗЫКЕ
}

\author{
ДАИКИ ХОРИГУТИ / DAIKI HORIGUCHI \\ Киотский университет (Япония) / Kyoto University \\ Graduate School of Human and Environmental Studies \\ Faculty of Integrated Human Studies \\ Division of Cognitive and Information Sciences \\ Yoshida-nihonmatsu-cho, Sakyo-ku, Kyoto 606-8501, Japan \\ E-mail: horiguchi.daiki.6x@kyoto-u.ac.jp \\ ORCID: https://orcid.org/0000-0003-0724-6209 \\ (Получено / Received 1.09.2020. Принято / Accepted 1.10.2020)
}

\section{Abstract \\ Russian prefix $z a$ - in connection with loan verbs}

This article provides some observations on how the Russian prefix $z a$ - functions in relation to loan verbs. Out of 270 unprefixed loan verbs, 241 verbs with the prefix $z a$ were attested and analyzed. Such a high activity (89.2\%) of the prefix can be explained by its wide polysemy. Among the high frequency verbs, the prefix demonstrates its perfectivizing function when its spatial semantics correlate with that of the base-verb or implicate it. For the rest of the $z a$-verbs, although less frequently used, inchoative and intensive semantics are observed. However, while inchoative semantics are recognized only among the verbs of certain semantic groups, intensive semantics are distributed more widely. Among loan verbs, several verbs denote the process of assigning 
some features to the object, and therefore suggest the degree of intensity of the action and productively connect to the verbs. On the other hand, among loan verbs, there are not many verbs that designate physical actions and are subjected to various spatial modifications. Spatial modification per se is not a characteristic of the prefixation of loan verbs.

Key words: prefix, loan verb, perfectivization, inchoative, intensity

\section{Резюме}

В статье отражены результаты наблюдений за функционированием префикса за- в сочетании с заимствованными глаголами ${ }^{1}$. Проанализирован 241 префиксальный глагол, образованный от 270 возможных базовых глаголов иноязычного происхождения. Высокая степень продуктивности префикса префикса за- объясняется его широкой полисемией. У высокочастотных глаголов доминирует перфективирующая функция, когда пространственная семантика базового глагола совпадает с семантикой префикса или имплицирует ее. У остальных, не столь употребительных глаголов можно констатировать инхоативную и интенсивную семантику. Однако если инхоативное значение приобретают глаголы определенных семантических разрядов, то шире наблюдается дистрибуция интенсивной семантики. Среди заимствованных глаголов немало глаголов, которые обозначают процесс приписывания объекту какого-либо признака, и соответственно предполагают степень интенсивности данного действия и легко сочетаются с данной семантикой. Наоборот, среди рассмотренных глаголов имеется небольшое количество глаголов, которые обозначают физическое действие и подвергаются различным пространственным модификациям. Поэтому в сочетании с заимствованными глаголами не так характерна собственно пространственная модификация.

Ключевые слова: префикс, заимствованный глагол, перфективация, инхоатив, интенсивность

\section{Вводные замечания}

По сравнению с аффиксацией давно укоренившихся исконных глаголов, которые рассматриваются как «уже готовые» производные, в аффиксации заимствованного глагола в большей степени отслеживается причастность говорящего к самому словообразовательному процессу. В этой связи деятельностный характер словообразования (Земская 2009: 4-5) наглядно демонстрируется в аффиксации заимствованных глаголов. Изучение аффиксации заимствован-

\footnotetext{
1 В работе используется сочетание «заимствованные глаголы» в значении «глаголы с заимствованной основой», к которым присоединяются русские аффиксы.
} 
ных глаголов также проливает свет на процесс лексико-грамматической адаптации посредством словообразования.

Префиксальные производные от заимствованных основ как новые лексические единицы могут требовать у читателя задействования метаязыковой рефлексии. Поэтому префиксальные глаголы в тексте нередко встречаются с пояснительным комментарием, графически оформляются с помощью скобок (Хоригути 2017:311): «Мы начали задавать вопросы, и нам сказали, что раз участок не засанирован (не заделан материалом. - Прим. «Новой»- Казахстан»), комиссия его принимать не будет» (Новая Газета Казахстан, 09.12.2015). В этом примере семантику производного засанирован может эксплицировать комментарий, который дается в виде примечания редакции.

Маркирование перфективности связано со стремлением выражать грамматическую видовую оппозицию в языке. Однако на практике этому препятствует узус, и при редактировании текста перфективирующий аффикс может быть удален (Хоригути 2017: 308-309; Хоригути 2018: 353-354). Ср. два предложения из одного и того же текста, цитируемого в разных источниках: Чемпионат был залииензирован тично президентом Международной Ассоииации «Что? Где? Когда?» (Любава On-line, 27.10.2009); Чемпионат был лицензирован Международной Ассоииацией «Что? Где? Когда?» (Вперед: дата публикации не указана). При редактировании текста наблюдается удаление других аффиксов. В неузуальных производных часть носителей языка может сомневаться, опираясь на их отсутствие в лексикографических источниках или порой субъективное языковое чутье. Например, у глагола замотивировать в нашем корпусе на конец 2019 года констатировано 41254 случая употребления. Однако говорящий, передавая чужую речь, отрицает существование глагола и при этом прибегает к эмоциональному паралингвистическому средству - восклицательному знаку: Недавно довелось усльишать, как один ведущий телепередачи радостно сообщил, что все зрители очень „замотивировань” (!) темой обсуждения. Видимо, он хотел сказать, что зрителей очень заинтересовала тема, но почему-то использовал слово, которого не существует в русском языке (мотивировать - есть, а „замотивировать" - нет), да еще и не подходящее по стилю (Россотрудничество, 20.08.2015).

Префиксация заимствованных глаголов представляет собой динамический языковой процесс, который следует описывать в тесной связи с текстом. Однако она традиционно изучается, в первую очередь, с аспектологической точки зрения. Как центральный вопрос обсуждается видовое (не)разграничение двувидовых глаголов преимущественно посредством префиксации. Поскольку в словообразовании важную роль играет аналогия, в подавляющем большинстве случаев префикс все-таки проявляет свой словообразовательный потенциал независимо от происхождения производящего глагола. Из-за этого реже затрагиваются особенности, которые можно обнаружить при сопоставлении префиксации заимствованных и исконных глаголов (Хоригути 2019: 266-267).

В этой статье отражены результаты наблюдений за функционированием префикса за- в сочетании с заимствованными глаголами. Проанализирован 241 префиксальный глагол, образованный от 270 возможных базовых глаголов ино- 
язычного происхождения. Базовые глаголы являются как глаголами $\mathrm{HCB}$, так и двувидовыми глаголами. Языковыми фактами послужили тексты, доступные в базе данных Интегрум (www.integrumworld.com) на конец июля 2020 года.

\section{Префикс за-}

Описанию семантики префикса за- посвящен целый ряд работ. Данный формант выделяется своей полисемией. Например, А. Богуславский составил перечень значений за-, в который входит 24 семы (Bogusławski 1963: 47-48, 52, 55, $57,63,65-67,75,79,84,90,113-115)$. Как наиболее репрезентативные значения префикса можно выделить пространственную семантику, а также инхоативную и интенсивную. Пространственная семантика тесно связана с функцией перфективации базового глагола. Префикс может выступать в качестве перфективирующего префикса, когда его пространственная семантика совпадает с той семантикой, которая вытекает из названного глаголом действия. Следует также обратить внимание на экспрессивные употребления префикса за-, который заменяет другие канонические префиксы в сфере разговорной речи, например, в молодежном и профессиональном сленге (Соколова 2009: 51-60; Ремчукова 2016: 188).

В контексте перфективации заимствованных глаголов префикс за- считается одним из префиксов, которые активно образуют видовые пары среди заимствованных глаголов. Среди 10 чистовидовых префиксов префикс за- занимает второе место (22\%) между префиксами с- (26\%) и про- (21\%) (Чанг 2016: 71). Наше исследование не ограничится анализом перфективации заимствованных глаголов с помощью префикса за-; ниже мы рассмотрим общую тенденцию функционирования данного форманта.

Количественный анализ показал, что среди 20 префиксов префикс за- является не просто одним из продуктивных префиксов, а самым продуктивным префиксом. Он присоединяется к подавляющему большинству глаголов, которое составляет $89.2 \%$ из общего количества базовых глаголов, оставляя далеко позади префиксы про- и $c$-.

При семантическом описании префикса за- неизбежно возникает вопрос его полисемии и омонимии производных слов. Без достаточного контекста определение семантики префикса затруднено. Например, если глаголы петь и столярничать тривиально относятся к глаголам деятельности, то запеть и застолярничать указывают на инхоативный способ действия. Однако в статье, озаглавленной «120 способов защиты от стресса», с прямым дополнением стресс префикс актуализирует семантику «удалить что-либо путем названного базовым глаголом действия». Приведем ряд за-глаголов, в том числе заимствованных: запеть стресс медитационным пением по Ошо Раджнишу. застолярничать стресс - утилизировать энергию стресса в полезное дело зарационализировать стресс, завизуализировать стресс, замедитировать стресс, заоптимизировать стресс, зафразировать стресс (Аргументы и факты. Здоровье: 16.09.2004). Определение семантики производного слова с пре- 


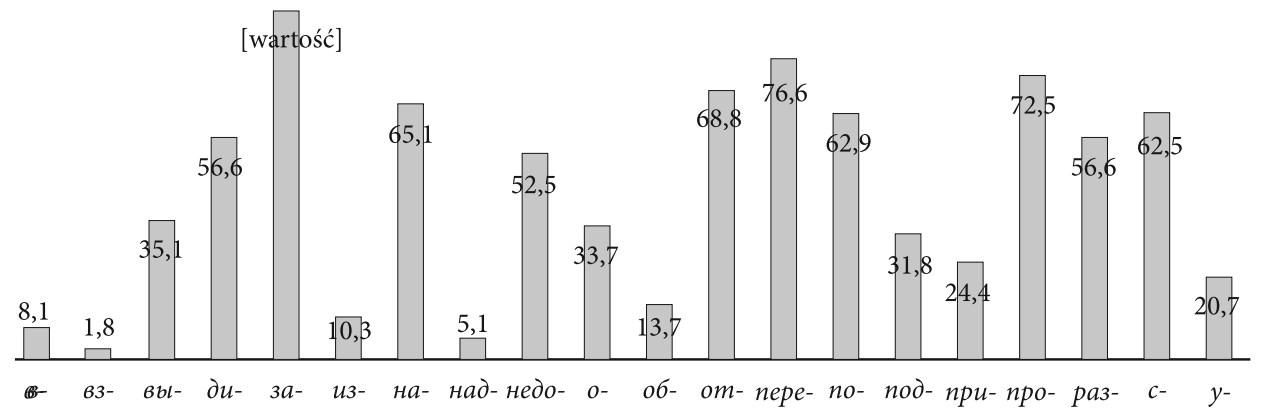

График 1. Сочетаемость префиксов с 270 заимствованными глаголами в процентном отношении.

фиксом осложняет не только полисемия префикса, но и принадлежность базового глагола к определенной семантической группе. Когда глагол анализировать обозначает мыслительный процесс, префикс обладает инхоативной семантикой: Марк зарделся и заанализировал про себя. (Петербургский театральный журнал: 15.05.2001). Однако когда речь идет о деятельностях, префикс вносит значение интенсивности: Его заинтервьюировали, заанализировали и заисследовали разве что не до смерти (Marketopic.ru: 28.01.2017). Таким образом, при анализе за-глаголов должны приниматься во внимание окружающие их слова.

\section{Эмпирические данные за-глаголов}

Констатированные в нашем материале за-глаголы по частоте употребления резко отличаются между собой - от единичных случаев вплоть до миллионов. Если рассмотреть за-глаголы по частотности, то в качестве наиболее употребляемых можно привести единицы, в которых префикс служит средством перфективации на основе общих семантических свойств префикса и базового глагола. Лексемы, выделенные подчеркиванием ниже, несомненно, представляют собой глаголы СВ по отношению к соответствующим базовым глаголам. Количественные данные в скобках указывают на число найденных в корпусе текстов, содержащих словоформы данного глагола: зарегистрировать (26791299), запланировать (20560344), зафиксировать (18284792), заинтересовать (15687606), заблокировать (4431292), зарекомендовать (1887505), задекларировать (1429116), запатентовать (758979), зарезервировать (634741), заасфальтировать (431633), запрограммировать (371622), замаскировать (316363), заинтриговать (238253), забетонировать (110703), закредитовать (77648), зарегулировать (63643), забаррикадировать (47264), загипнозировать (45840), забюрократизировать (42987), замотивировать (41217), защементировать (36364), запротестовать (32431), забальзамировать (30020), задекорировать (27524), запломбировать (20259), заполитизировать (13075), зарегламентировать (9151), зазомбировать (9175), заорганизовать (6361), закомментировать (4086), залицензировать (3112), замаркировать (2601), зацитировать (1659), закристаллизовать (1643), застабилизировать (1628). 
С перфективирующим префиксом за- сочетаются широкие, но определенные семантические группы глаголов. П. Чанг выделяет 9 семантических групп: 'покрывать что-л. чем-л.', 'заполнять чем-л.,' 'заносить, отмечать что-л. в письменном документе', 'закреплять за кем-л. или чем-л. предмет, названный в прямом дополнении', 'осуществлять какое-л. действие с помощью какого-л. предмета или мыслей', 'ставить, накладывать что-л. на предмет, указанный в прямом дополнении', 'завязывать, обматывать, заворачивать предмет, названный в прямом дополнении', 'заготовлять что-л. для сохранения', 'делать то, что названо в прямом дополнении, незаметным, тайным' (Чанг 2016: 74-76). Большинство приведенных выше глаголов относятся к подобным семантическим группам. Базовые глаголы функционируют как глаголы НСВ, а не как двувидовые: Часто чиновники декларируют то, что не задекларировать невозможно (ИА REGNUM, 02.10.2017); Кстати, на улице Городоикой начали бетонировать дорогу, а Льчаковскую забетонировали уже наполовину (Комсомольская правда, Львов: 05.10.2011); Вас ведь никто не зомбировал, вы сами себя зазомбировали и продолжаете зомбировать (Cogita!ru, 02.04.2016).

В тексте нередко наблюдается ряд однопрефиксальных глаголов, которые выступают как однородные члены предложения. Это показывает категориальность семантики префикса и глаголов: Часть дорожек в скверах заасфальтируют, а часть забетонируют (Версия Инфо, 11.10.2017); Можно бороться с нелегальным рынком административно: ужесточить, законтролировать, заквотировать, залицензировать (Комсомольская правда, 13.03.1999); Mbl зафиксировали, застабилизировали всю кредиторскую задолженность, реструктурировали её, и на сегодняшний день мы реально её погашаем (Knews, 14.10.2003).

В отдельных глаголах префикс за- лексикализован и не соотносит производный глагол с базовым в плане аспектуальной оппозиции. Например, глагол закомментировать относится к профессионализмам специалистов IT-сферы в значении «пометить строку кода». Глагол зарекомендовать «проявить себя для репутации» имеет вторичный имперфектив, на чем остановимся подробнее.

Некоторые за-глаголы уже закрепились как перфективные глаголы по отношению к базовому глаголу и допускают вторичные имперфективы. Часть из за-глаголов составляют так называемую аспектуальную тройку (маскировать - замаскировать - замаскировывать). Как известно, суффиксации могут подвергаться глаголы на -ова́-/-ирова́-, то есть с конечным ударным -á-. В пределах этого морфонологического ограничения констатировано 16 вторичных имперфективов: заинтересовывать (58869), зашифровывать (15763), замаскировывать (1131), зарекомендовывать (1016), закредитовывать (780), запатентовывать (470), заорганизовывать (426), запломбировывать (59), занумеровывать (38), затренировывать (15), зааттестовывать (8), закритиковывать (3), застилизовывать (6), зарапортовывать (5), закристаллизовывать (5), зацентрализовывать (4), заморализовывать (1). Примеры показывают, что глаголы составляют полноценную видовую оппозицию. В инфинитивной форме глагол НСВ в сочетании с нельзя указывает на запрет, а глагол СВ с частицей не - на невозможность: Нельзя замаскировывать словом «товарищ» глубокий, имуще- 
ственный, социальный и духовный раскол в обществе. (...) Раскол в обществе не замаскировать (Белгородская правда, 25.06.2010). Глагол НСВ в настоящем времени описывает хабитуальное действие, а глагол СВ соотносится с понятием целостности действия: По их словам, нередко хозяева «замаскировывают» их под постоянное жилье, которое стоит дороже, вводя таким образом арендаторов в заблуждение (...). Однако риэлтор говорит, что «замаскировать» их под постоянное жилье достаточно трудно (...) (Деловой квартал, 05.05.2011).

Вопреки морфонологическому ограничению, у глаголов на - и'рова- констатировано также 6 неканонических вторичных имперфективов: зарегулировывать (5), зататуировывать (4), закомментировывать (3), заасфальтировывать (3), заблокировывать (3), законвоировывать (3). Во всех случаях употребления таких глаголов характерны явные имперфективные контексты (Хоригути 2018: 352-353).

Префиксом за- инхоативность выражается в сочетании с глаголами, которые обозначают деятельность, занятие, а также воспринимаемые чувствами явления и ментально-психические действия (Петрухина 2011: 197-200, Bottineau 2014: 267). Однако так как среди рассмотренных заимствованных глаголов мало базовых глаголов, которые относятся к данной семантической группе, выражаемая префиксом инхоативная семантика, не представлена столь широко среди заимствованных глаголов: заинтересовать, заинтриговать, зафункиионировать, зааккомпанировать засигнализировать, заанализировать заангажировать, загипнотизировать, замотивировать: (...) заработает выездная торговля, зафункиионируют специально установленные туалеты (Марийская правда, 18.01.2016); Кто-то добрался до пианино и зааккомпанировал (Московский комсомолец, 03.03.2008); Хозяйка авто закрыла двери на сигнализацию и пошла $\kappa$ дому. Ожидая лифт, она услышала, как засигнализировал брелок (Городские известия, 01.02.2014); Лужкова вызвали на сцену, и Иглесиас буквально заставил двух дорогих гостей спеть ему «Очи черные». Мэр сначала было запротестовал, но потом честно затянул первый куплет, после чего пустился плясать «Цыганочку» к вящей радости всего зала (Аргументы и факты, 17.06.1998).

У менее частотных глаголов широко представлена интенсивная семантика префикса. Глаголы относятся к чрезмерно-продолжительному способу действия. Данная семантика объясняется так: 'довести кого-что-л. до нежелательного состояния (негодности, утомления, исчерпанности) посредством действия, названного мотивирующим глаголом' (Русская грамматика 1980: 360) - и выражает 'чрезмерную частотность или продолжительность воздействующего действия, в результате чего объект приобретает отрицательное состояние' (Шелякин 2008: 149). Наиболее частотными интенсивными за-глаголами являются заорганизовать и зарегламентировать. Другие примеры: От нас, из Москвы, Европа иногда кажется перенаселенной, заиндустриализированной (BFM.ru, 31.07.2013); Эту комиссию зафантазировала и заполитизировала, к сожалению, пресса (УНИАН, 03.06.2011); (..) эти шоу всегда завалены рекламой, заспонсированы спонсорами, забрендированы торговыми марками (Теленеделя, Одесса, 09.07.2012). 
Обратим внимание, что многие из констатированных за-глаголов в этом значении обозначают процесс наделения объекта каким-либо признаком. Эта семантика присуща в частности для ряда глаголов на -изирова-. Наиболее часто найденными формами являются причастия прошедшего времени как в краткой, так и полной форме. Внимание акцентируется на состоянии, которое возникло в результате той или иной ситуации: Ошибкой было то, что этот процесс был излишне заполитизирован и занационализирован (Об'єктивНо, Харьков, 04.12.2008); А в какую церковь бежать? В эту - заполитизированную, закомерциализированную, почти закриминализированную? (День, Киев, 05.04.2012). Частотный глагол заорганизовать чаще всего употребляется в этой форме: Во-первых, все было жестко организовано, если не сказать, заорганизовано: по пять минут отводили на голосование по судьбоносным документам, которье многие из делегатов толком и не успели прочесть (Московский комсомолец, 24.10.2001).

Префиксальные глаголы в данном значении часто сопровождает целый ряд наречий и наречных словосочетаний, уточняющих значение полисемного префикса: слишком, излишне, избыточно, чересчур, чрезмерно, чрезвычайно, с лихвой, сверх мерь, насмерть, насквозь, вусмерть, сплошь, донельзя, в прах, вовсю, вконеи, совсем, сильно, очень, крайне, максимально, в высшей/значительной степени, до такой степени (, что), настолько (, что), так (, что), до того (, что). Весьма характерны предложные словосочетания с помощью предлога до-. Говорящий прибегает к таким гиперболическим средствам и выражает максимально негативное отношение к действительности: до полусмерти, до предела, до абсолюта, до полной утрать, до оскомины, до безобразия, до идиотизма, до абсурда, до беспамятства, до невозможности, до неузнаваемости, до тошноmol, до одурения, до потери сознания и др. Два наиболее часто встречающихся словосочетания - до дыр и до смерти. Примеры: Я тогда настолько перетрудил роль, так замордовал и зарепетировал ее до дьр, что там уже ничего живого не осталось (Огонек, 29.07.2003); Мь заребормировали его (иудаизм - примечание автора) до смерти, законсервировали его до смерти, зареконструировали его до смерти (Agoll, 24.11.2013). Глагол законсервировать считается стилистически нейтральным глаголом СВ, соотносимым с глаголом НСВ консервировать. Однако в силу контекстуального окружения - ряда однопрефиксальных глаголов и словосочетания до смерти - у него преобладает интенсивная семантика.

В заключение рассмотрим особенности префикса за-, которые проявляются в префиксации исконных глаголов, но не наблюдаются в сочетании с заимствованными глаголами. Несмотря на наличие у префикса за- нескольких пространственных значений, его пространственная семантика не столь явно актуализируется в сочетании с заимствованными глаголами. Это объясняется тем, что среди заимствованных глаголов мало глаголов, которые толерантно относятся к разным пространственным модификациям и имеют богатую в пространственном плане словообразовательную парадигму. Среди исконных глаголов это, в первую очередь, глаголы движения (идти, нести), а также глаголы физических действий (клеить, винтить), которые могут подвергаться различным пространственным модификациям (войти/пройти, приклеить/наклеить). 
Определенная часть заимствованных глаголов имеет абстрактную семантику, что препятствует проявлению пространственных значений префикса за- в префиксации заимствованных глаголов. При актуализации своей пространственной семантики префикс скорее функционирует как маркер перфективности, а не как пространственный модификатор. В отличие от интенсивного способа действия, смягчительный способ действия, значение которого можно было бы усмотреть в единичных исконных за-глаголах (Ушакова 2009: 113), не выявлен среди заимствованных глаголов. Мутационные образования, которые встречаются среди некоторых исконных глаголов (заработать 'приобрести работой'), также не представлены в рассмотренном материале.

\section{Выводы}

В силу взаимодействия полисемии префикса и неустойчивости лексико-семантического разряда базового глагола невозможно количественно определить распределение словообразовательных моделей среди заимствованных глаголов. Высокая присоединяемость префикса за- объясняется его широкой полисемией. У высокочастотных глаголов доминирует перфективирующая функция, когда пространственная семантика базового глагола совпадает с семантикой префикса или имплицирует ее. У остальных, не столь употребительных глаголов, можно констатировать инхоативную и интенсивную семантику. Однако если инхоативное значение приобретают глаголы определенных семантических разрядов, то шире наблюдается дистрибуция интенсивной семантики. Среди заимствованных глаголов немало глаголов, которые обозначают процесс приписывания объекту какого-либо признака и, соответственно, предполагают степень интенсивности данного действия и легко сочетается с данной семантикой. Наоборот, среди рассмотренных глаголов имеется небольшое количество глаголов, которые обозначают физическое действие и подвергаются различным пространственным трансформациям. В этой связи в сочетании с заимствованными глаголами для рассматриваемого форманта не так характерна собственно пространственная модификация.

\section{Библиография / References}

Bogusławski, A. (1963). Prefiksacja czasownikowa we współczesnym języku rosyjskim. Wrocław-Warszawa-Kraków: Zakład Narodowy im. Ossolińskich.

Bottineau, T. (2014). Inhoativnye glagoly s prefiksom za-, ili glavnoe načat', i process pošel. Russian Linguistics, 38, 261-276 [Bottineau, Т. (2014). Инхоативные глаголы с префиксом за-, или главное начать, и прочесс пошел. Russian Linguistics, 38, 261-276].

Čang, P.-Č. (2016). Processy assimilâcii zaimstvovannyh glagolov v sovremennom russkom âzyke: morfologičeskij i semantičeskij aspekty. Tajbèj: Student Book [Чанг, П.-Ч. (2016). Процесcьь ассимиляиии заимствованных глаголов в современном русском языке: морбологический и семантический аспекты. Тайбэй: Student Book].

Horiguti, D. (2017). Metaâzykovaâ refleksiâ v zerkale prefiksacii zaimstvovannyh glagolov v russkom âzyke. V: Iǔčankaǔ, V. (Red.). Stylistyka: mova, maǔlenne i tèkst: 27-32 [Хоригути, Д. (2017). 
Метаязыковая рефлексия в зеркале префиксации заимствованных глаголов в русском языке. В: Іўчанкав, В. (Ред.). Стылістыка: мова, маўленне і тэкст 27-32].

Horiguti, D. (2018). Imperfektivaciâ zaimstvovannyh glagolov v russkom âzyke. Russian Linguistics, 42 (3): 345-356 [Хоригути, Д. (2018). Имперфективация заимствованных глаголов в русском языке. Russian Linguistics, 42 (3): 345-356].

Horiguti, D. (2019). Realizaciâ sintaksičeskih konstrukcij u prefiksal'nyh zaimstvovannyh glagolov v russkom âzyke. V: Szumska, D., Ozga, K. (Red.). Âzyk i metod, 6: 259-268 [Хоригути, Д. (2019). Реализация синтаксических конструкций у префиксальных заимствованных глаголов в русском языке. B: Szumska D., Ozga, K. (Ред.). Язык и метод, 6: 259-268].

Petruhina, E.V (2011). Aspektual'nye kategorii glagola v russkom âzyke v sopostavlenii s češskim, slovackim, pol’skim i bolgarskimi jazykami. 2-e izd. Moskva: Knižnyj Dom «LIBROKOM» [Петрухина, Е.В. (2011). Аспектуальные категории глагола в русском языке в сопоставлении с чешским, словацким, польским и болгарским языками. 2-е изд.. Москва: Книжный Дом «ЛИБРОКОМ»].

Remčukova, E.N. (2016). Kreativnyj potencial russkoj grammatiki. Moskva: Knižnyj Dom «LIBROКОМ» [Ремчукова, Е.Н. (2016). Креативный потенциал русской грамматики. Москва: Книжный Дом «ЛИБРОКОМ»].

Russkaja grammatika (1980). T. 1. Moskva: Nauka [Русская грамматика (1980). Т. 1. Москва: Наука].

Sokolova, S. (2009). «Zasmotrite i zacenite»: produktivnost' pristavki $z a-v$ sovremennom russkom âzyke. Polârnyj vestnik, 12: 43-63 [Соколова, С. (2009). «Засмотрите и зацените»: продуктивность приставки за- в современном русском языке. Полярный вестник, 12: 43-63].

Ušakova, L.I. (2009). O polifunkcional'nosti glagol’nogo prefiksa za-. Vestnik Voronežskogo gosudarstvennogo universiteta. Seriâ: filosofiâ. Žurnalistika, 1: 111-115 [Ушакова, Л.И. (2009). О полифункциональности глагольного префикса за-. Вестник Воронежского государственного университета. Серия: философия. Журналистика, 1: 111-115].

Šelâkin, M.A. (2008). Kategoriâ aspektual'nosti russkogo glagola. Moskva: Izdatel’stvo LКI [Шелякин, М.А. (2008). Категория аспектуальности русского глагола. Москва: Издательство ЛКИ].

Zemskaâ, E.A. (2009). Slovoobrazovanie kak deâtel’nost'. 4-e izd. Moskva: Knižnyj Dom «LIBROКОМ» [Земская, Е.А. (2009). Словообразование как деятельность. 4-е изд. Москва: Книжный Дом «ЛИБРОКОМ»].

Competing interests: The author declares that he has no competing interests. 